\title{
Revista do Estado do Espírito Santo: análises gráfica e editorial
}

\author{
Revista do Estado do Espírito Santo, a periodical from the 1930s: \\ graphic and editorial analysis
}

Amanda Martinelli das Neves, Letícia Pedruzzi Fonseca

imprensa, revista, projeto editorial, análise gráfica

No início do século XX, surgiram diversos tipos de publicações no Brasil e dentre as novas possibilidades estavam as revistas com páginas recheadas de ilustrações e fotografias, atraindo os olhos do consumidor. No Espírito Santo, averiguou-se o aumento da quantidade de revistas em circulação na década de 1930 e dentro desse contexto foi escolhida para essa pesquisa a Revista do Estado do Espírito Santo, lançada em 1933, com forte apelo comercial e investimentos em sua produção gráfica. Para a realização de sua análise gráfica e editorial utilizou-se como base o conjunto metodológico para pesquisa em história do design a partir de materiais impressos (Fonseca et al., 2016). Os resultados mostraram que as estratégias adotadas pela revista eram apoiadas pelo seu forte apelo comercial, com grande espaço para os anúncios, investimentos que incluíram impressão em cores da capa, muitas imagens, elementos decorativos e composições inovadoras nas páginas, além de conteúdo variado para atender aos interesses do público.

press, magazine, editorial project, graphic analysis

At the beginning of the 20th century, several types of publications appeared in Brazil and among the new possibilities were magazines with pages full of illustrations and photographs, attracting the eyes of the consumer. In Espirito Santo, there was an increase in the number of magazines in circulation in the 1930s and within this context, Revista do Estado do Espirito Santo was uded for this research, launched in 1933, with a strong commercial appeal and investments in its graphic production. To carry out its graphic and editorial analysis, the methodological set for researching design history from printed materials was used as a base (Fonseca et al., 2016). The results showed that the strategies adopted by the magazine were supported by its strong commercial appeal, with great space for ads, investments that included printing in colors of the cover, many images, decorative elements and innovative compositions on the pages, in addition to varied content to meet to the interests of the public.

\section{Introdução}

No início do século $X X$, o Brasil vivia uma crescente evolução industrial e isso estimulou o surgimento de diversos tipos de publicações. Dentre as novas possibilidades, as revistas passaram a adotar um modelo que se consolidou, com páginas recheadas de ilustrações e fotografias, atraindo os olhos do consumidor (Baptista \& Abreu, 2010).

Considerando o desenvolvimento da produção de revistas no início do século $X X$, utilizouse os dados do inventário de revistas capixabas produzidos pelo Laboratório de Design:

Anais do $10^{\circ} \mathrm{CIDI}$ e $10^{\circ} \mathrm{CONGIC}$

Kelli C.A.S. Smythe, Rafael de Castro Andrade (orgs.)

Sociedade Brasileira de Design da Informação - SBDI

Curitiba | Brasil | 2021
Proceedings of the $10^{\text {th }} \mathrm{CIDI}$ and $10^{\text {th }}$ CONGIC

Kelli C.A.S. Smythe, Rafael de Castro Andrade (orgs.)

Sociedade Brasileira de Design da Informação - SBDI Curitiba | Brazil | 2021 
História e Tipografia (LadHT), que registrou o princípio desse mercado no Espírito Santo, nos moldes das publicações nacionais. Além disso, averiguou-se o aumento da quantidade de revistas em circulação na década de 1930, tendo sido encontrados sete títulos nos acervos públicos da Região Metropolitana da Grande Vitória, dois títulos a mais do que os verificados na década de 1920.

Nesse contexto, o presente artigo objetiva analisar gráfica e editorialmente a Revista do Estado do Espírito Santo (1933), que tinha forte apelo comercial e investimentos relacionados à publicação de imagens e às experimentações em relação a sua composição.

\section{Metodologia}

Adotou-se o conjunto metodológico para pesquisa em história do design a partir de materiais impressos, para a sistematização desta pesquisa, que se baseia em duas etapas, sendo a primeira a aproximação do pesquisador com o contexto sócio-histórico que consistia em uma revisão bibliográfica e, a segunda, a análise gráfica do mesmo, pautada no mapeamento e identificação dos acervos públicos; registro fotográfico; organização do acervo digital; elaboração da ficha coleta de dados; aplicação da ficha; análise estatística e discussão dos resultados (Fonseca et al., 2016).

A escolha da revista ocorreu no processo de verificação do inventário de revistas capixabas, produzido pelo LadHT, onde foi possível, através de seu registro fotográfico, obter informações pertinentes que auxiliaram na condução da pesquisa.

Este periódico pode ser encontrado na Biblioteca Pública do Espírito Santo Levy Cúrcio Rocha (BPES) e só possui a edição inaugural localizada. Para a análise gráfica e editorial foram considerados os seguintes aspectos: título, ano de publicação, formato, capa, miolo, estrutura das páginas, tipografias, ilustrações e/ou fotografias, anúncios, vinhetas ${ }^{1}$ e experimentações que não entram nas categorias acima. Na avaliação dos anúncios utilizou-se o método proposto por Azerêdo e Fonseca (2016), que os classificava em tipográficos e imagéticos.

\section{Revista do Estado do Espírito Santo}

A Revista do Estado do Espírito Santo foi lançada em 1933, com distribuição gratuita, 60 páginas, 17,3 × 25,5 cm, impressa na Empresa Graphico-Editora "Vida Capichaba", na cidade de Vitória, com capa colorida e miolo preto e branco. A publicação se caracteriza por apresentar uma miscelânea temática, com grande enfoque em atualidades e textos artísticos. Além disso, também identificou-se investimentos em recursos gráficos, como, fotografias, ilustrações pictóricas, títulos ilustrados e vinhetas decorativas.

\footnotetext{
${ }^{1}$ Ornato tipográfico, baseado em linhas geométricas, flores, folhagens, sêres vivos ou coisas inanimadas, para servir de enfeite ou cercadura em páginas de composição e trabalhos de fantasia." (Porta, 1958, p.412).
} 
No expediente da edição inaugural, a revista divulga que teria tiragem de 5000 exemplares e indica a variedade de locais elitizados em que seria distribuída gratuitamente, o que denota suas intenções comerciais com a venda de anúncios:

(...) ao commercio e seus freguezes, industria, medicos, dentistas, advogados, hoteis, cinemas, salões de barbeiros, clubs esportivos, associações de classe, a bordo dos transatlanticos e em todos os pontos de reunião pública na capital, interior e em todo o Brasil " (Revista do Estado do Espírito Santo, $\left.\mathrm{n}^{\circ} 1,1933, \mathrm{p.20}\right)$.

A revista convida colaboradores externos, como comerciantes, industriais, clubes esportivos ou o público em geral, a enviarem assuntos ou fotografias a serem divulgados gratuitamente, desde que, aprovado pela direção da revista. Também divulgava uma tabela de preços relacionados a publicação de anúncios, onde os valores variavam de acordo com o tamanho e localização na capa ou no miolo (figura 1).

Figura 1: Revista do Estado do Espírito Santo, $n^{\circ} 1,1933$, p. 20. Fonte: Acervo digital do Laboratório de Design: História e Tipografia (2020).
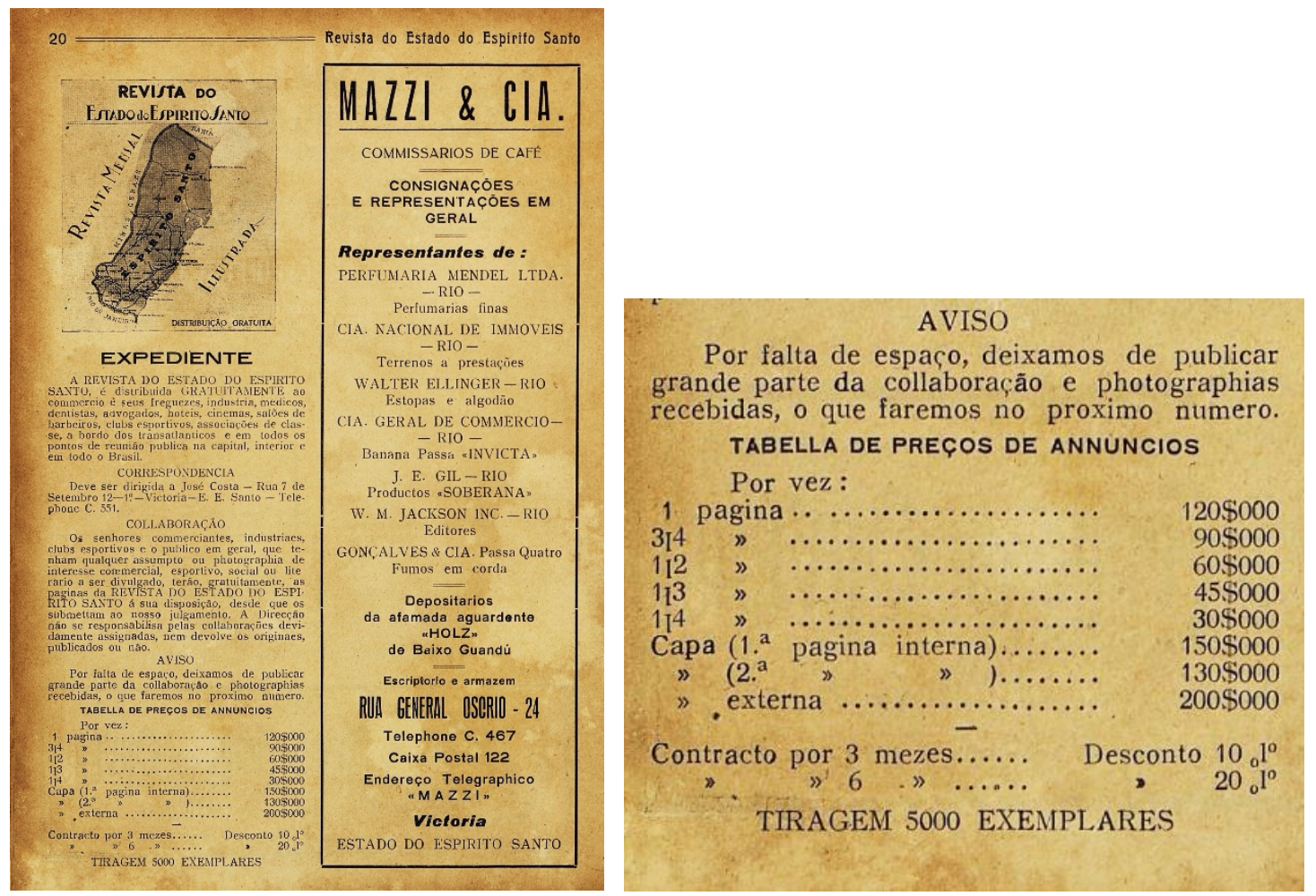

O periódico apresentou capa colorida, com o título da revista produzido em lettering e o uso predominante de um tom de azul e vermelho. Outro elemento de destaque foi uma ilustração do mapa do Estado do Espírito Santo em 4 cores ocupando quase toda a área da capa. No rodapé, estão os dizeres "distribuição gratuita" em vermelho, para chamar atenção do leitor (figura 2). 
Figura 2: Revista do Estado do Espírito Santo, n 1, 1933, capa. Fonte: Acervo digital do Laboratório de Design: História e Tipografia (2020).

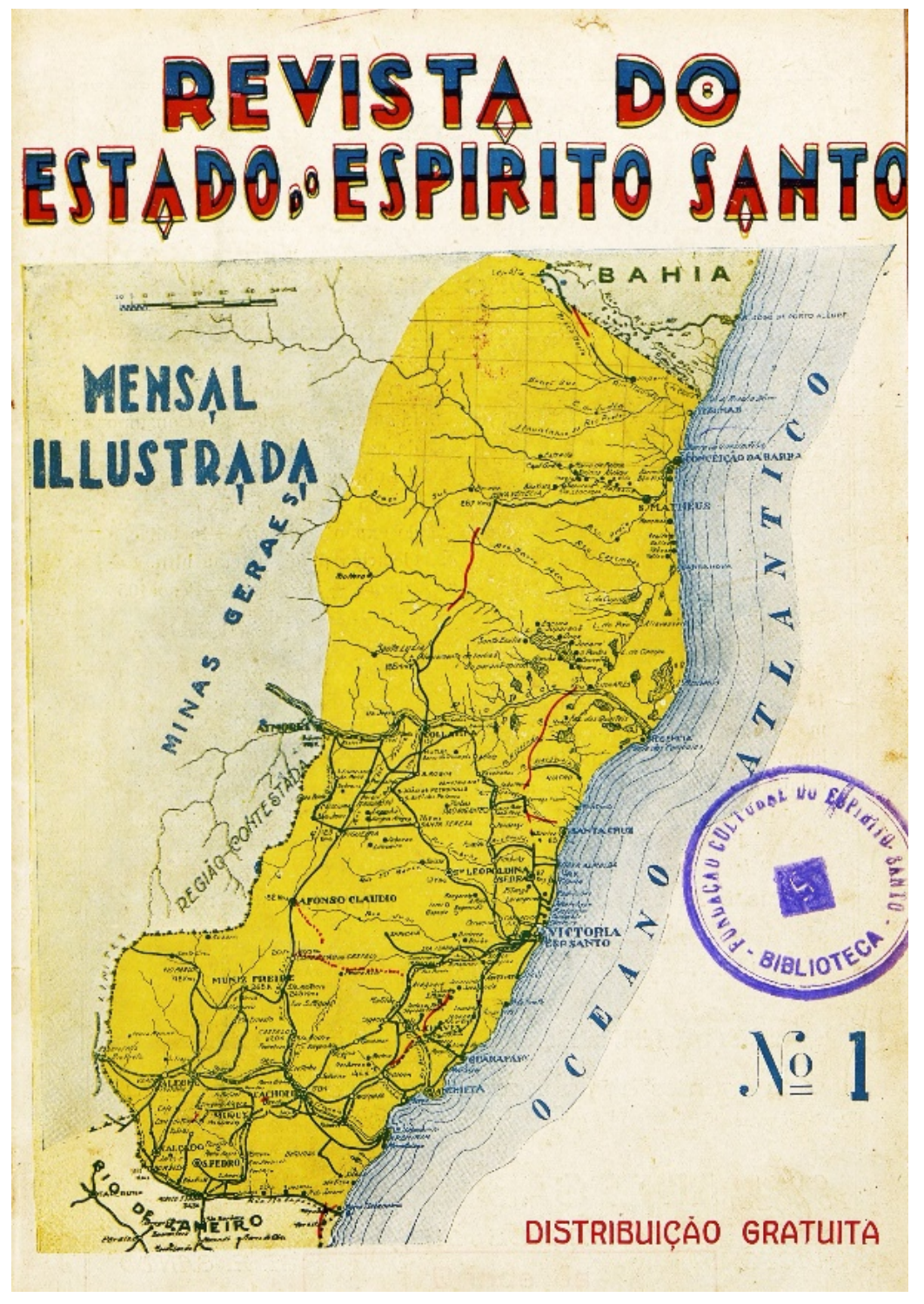

O miolo da revista possui uma configuração gráfica de uma a duas colunas de textos com alinhamento justificado e recuo na primeira linha. Além disso, apresenta um cabeçalho com o número da página e o nome da revista refletidos em páginas pares e ímpares. Um destaque interessante está no uso de lettering em títulos como o da página 10 (figura 3) que cria uma identidade para a matéria. 
Figura 3 e 4: Revista do Estado do Espírito Santo, n 1, 1933, p. 10 e 11. Fonte: Acervo digital do Laboratório de Design: História e Tipografia (2020).
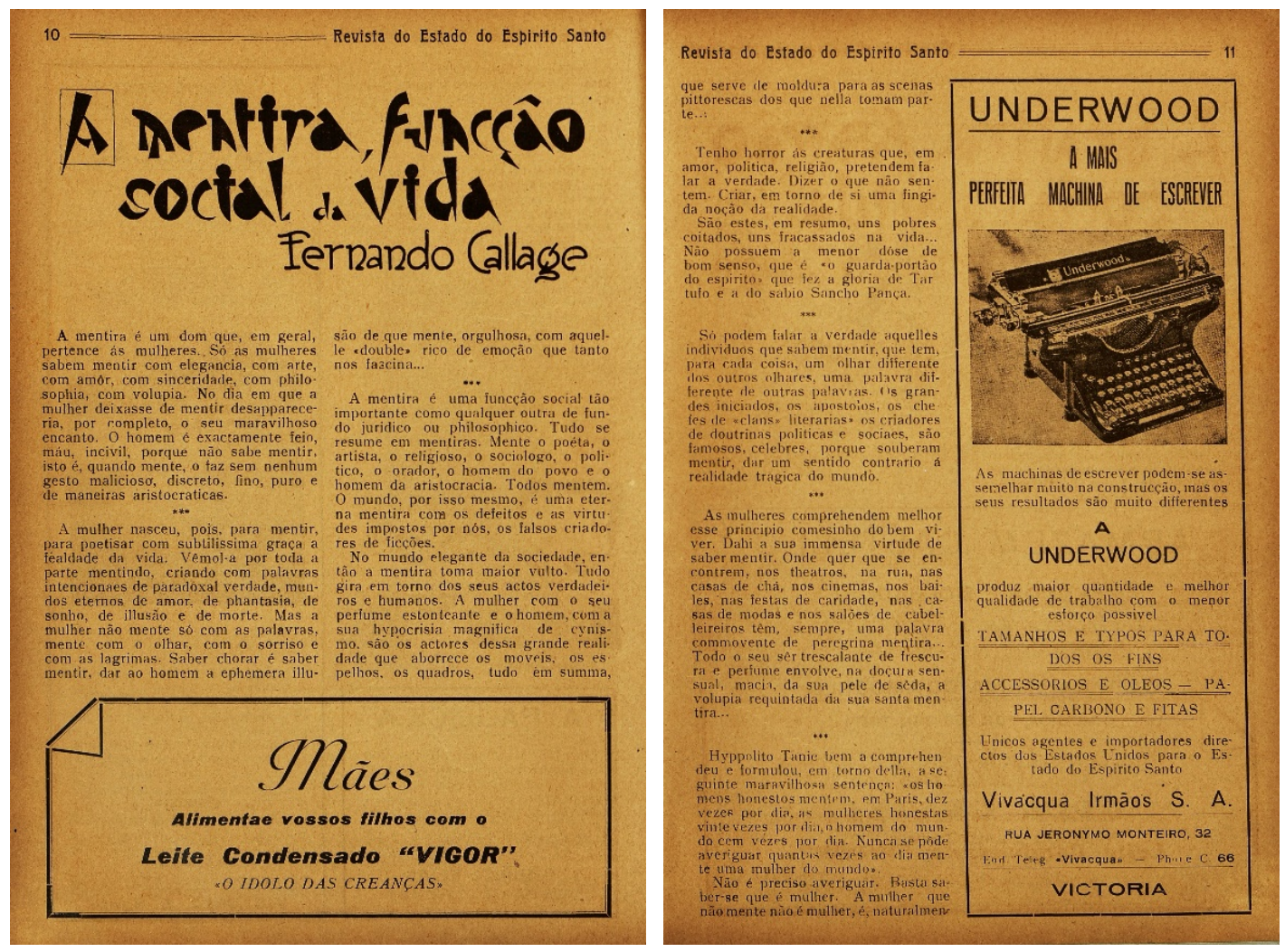

A revista apresenta ainda algumas manipulações da mancha gráfica, como pode ser visto na figura 5, onde verifica-se a aplicação de uma composição geometrizada na estruturação de seu texto. O periódico também se destaca por suas fotomontagens, como a construída na página 21 (figura 5), em que o título aparece junto à imagem recortada do convento, com o uso de letras no estilo art déco. Outro exemplo interessante pode ser percebido na figura 6 , em que há uma sobreposição de recortes fotográficos de diferentes formatos em uma composição retangular que ocupa grande parte da página, se assemelhando a um mosaico. 
Figuras 5 e 6: Exemplo de manipulação da mancha gráfica do texto, na Revista do Estado do Espírito Santo, n¹, 1933, p.21 e 36. Fonte: Acervo digital do Laboratório de Design: História e Tipografia (2020).
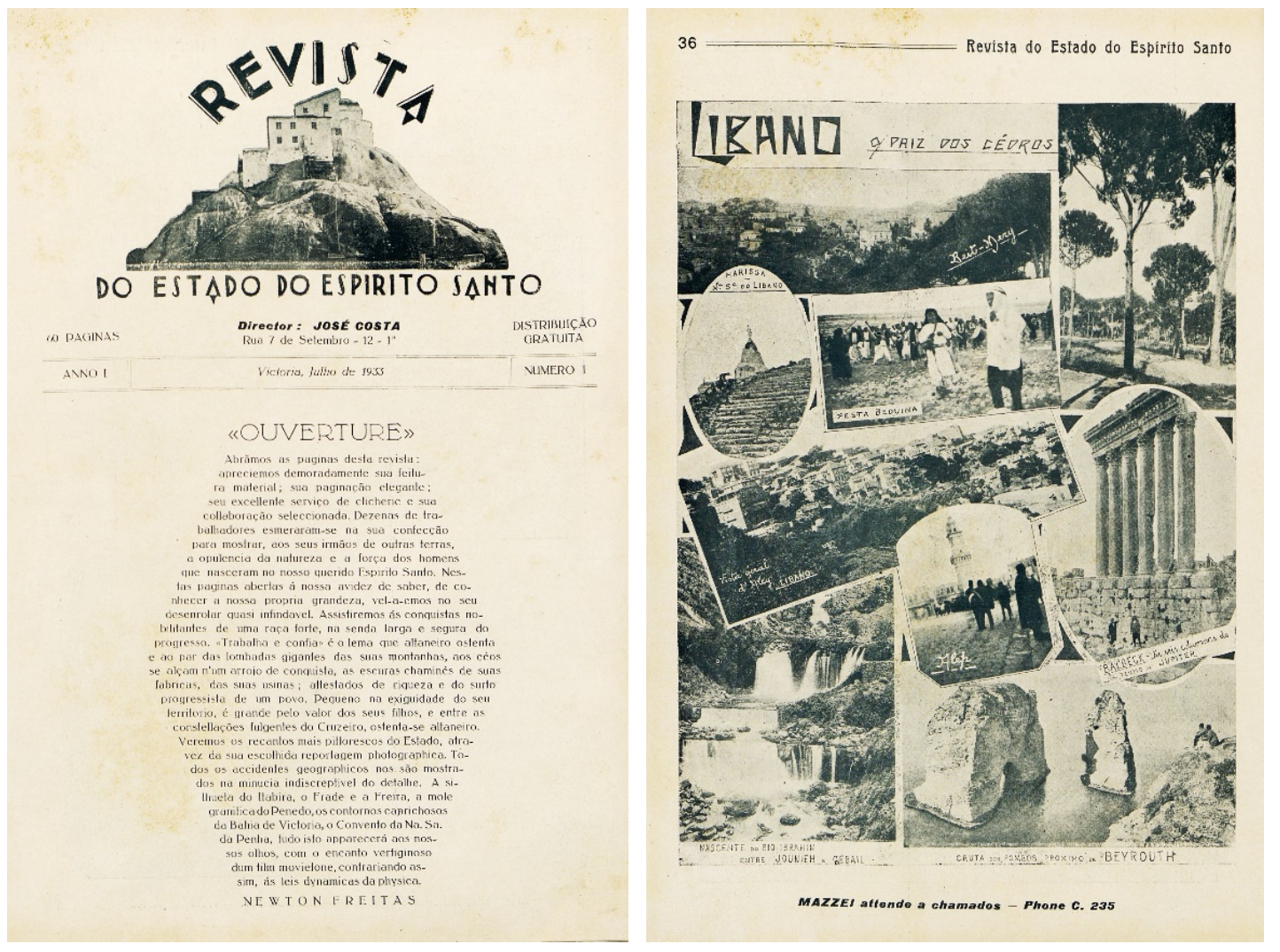

Em relação à classificação de seus anúncios, foram identificados os tipográficos e os imagéticos, sendo este último caracterizado pela presença de ilustrações e fotografias. Todos os anúncios eram caracterizados por uma moldura simples ou ornamentada, usada como forma de diferenciar seu conteúdo das matérias, e, consequentemente, se destacar na página. O peso tipográfico era maior no nome do estabelecimento, para direcionar a atenção do leitor para o anunciante, por meio de arranjos tipográficos que davam mais ênfase a algumas informações (figuras 7 a 12). 
Figura 7:Revista do Estado do Espírito Santo, n¹, 1933, segunda capa. Fonte: Acervo digital do Laboratório de Design: História e Tipografia (2020).

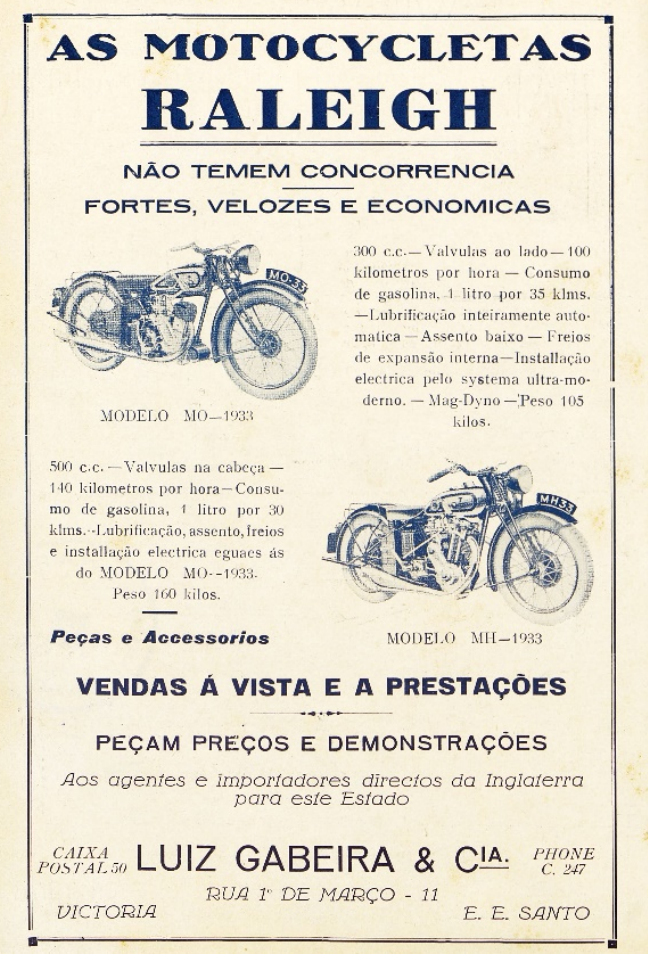

Figura 8 e 9: Revista do Estado do Espírito Santo, n¹, 1933, p. 1 e 2. Fonte: Acervo digital do Laboratório de Design: História e Tipografia (2020).
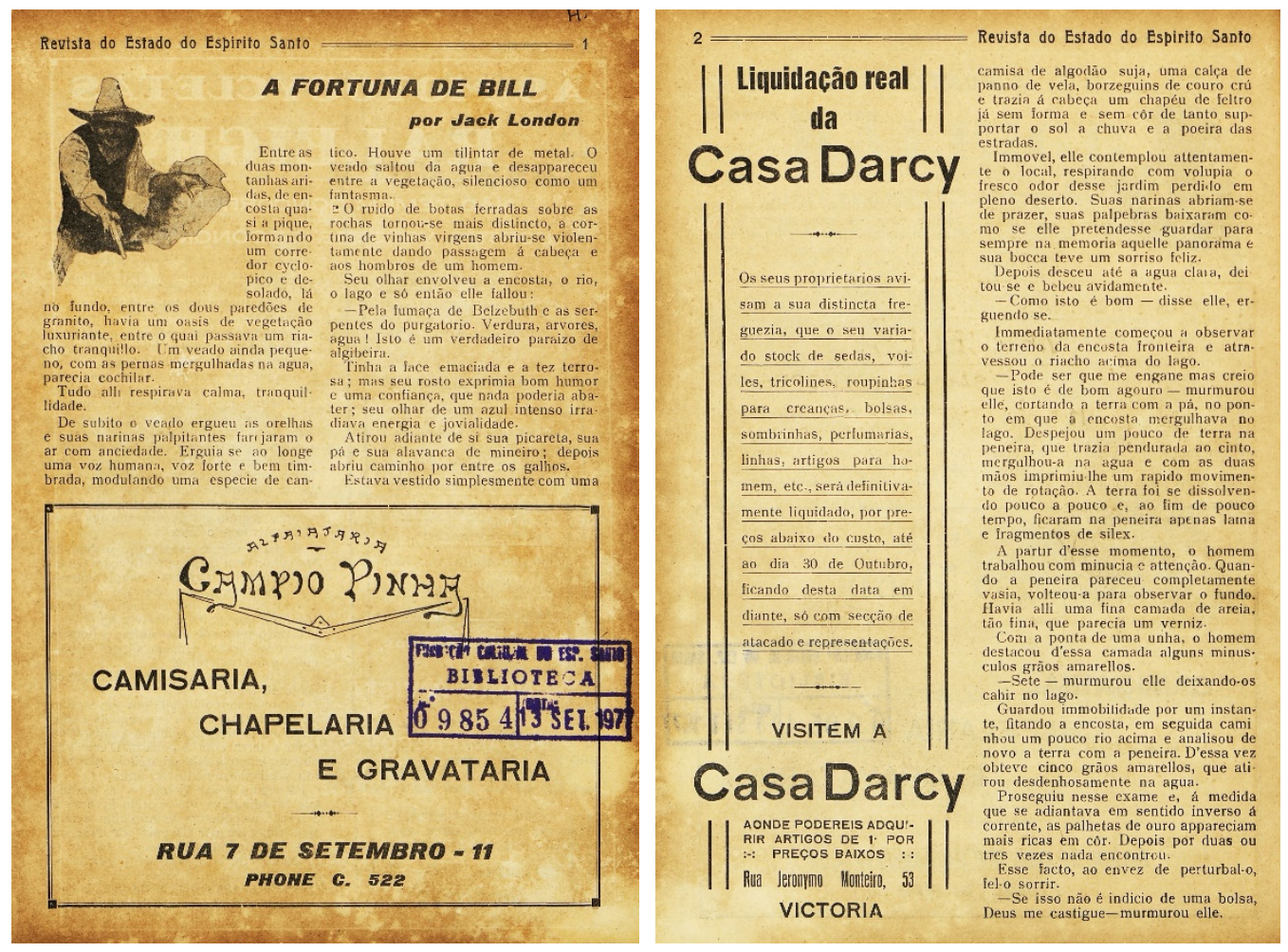
Figura 10 e 11: Revista do Estado do Espírito Santo, n¹, 1933, p. 3 e 7. Fonte: Acervo digital do Laboratório de Design: História e Tipografia (2020).
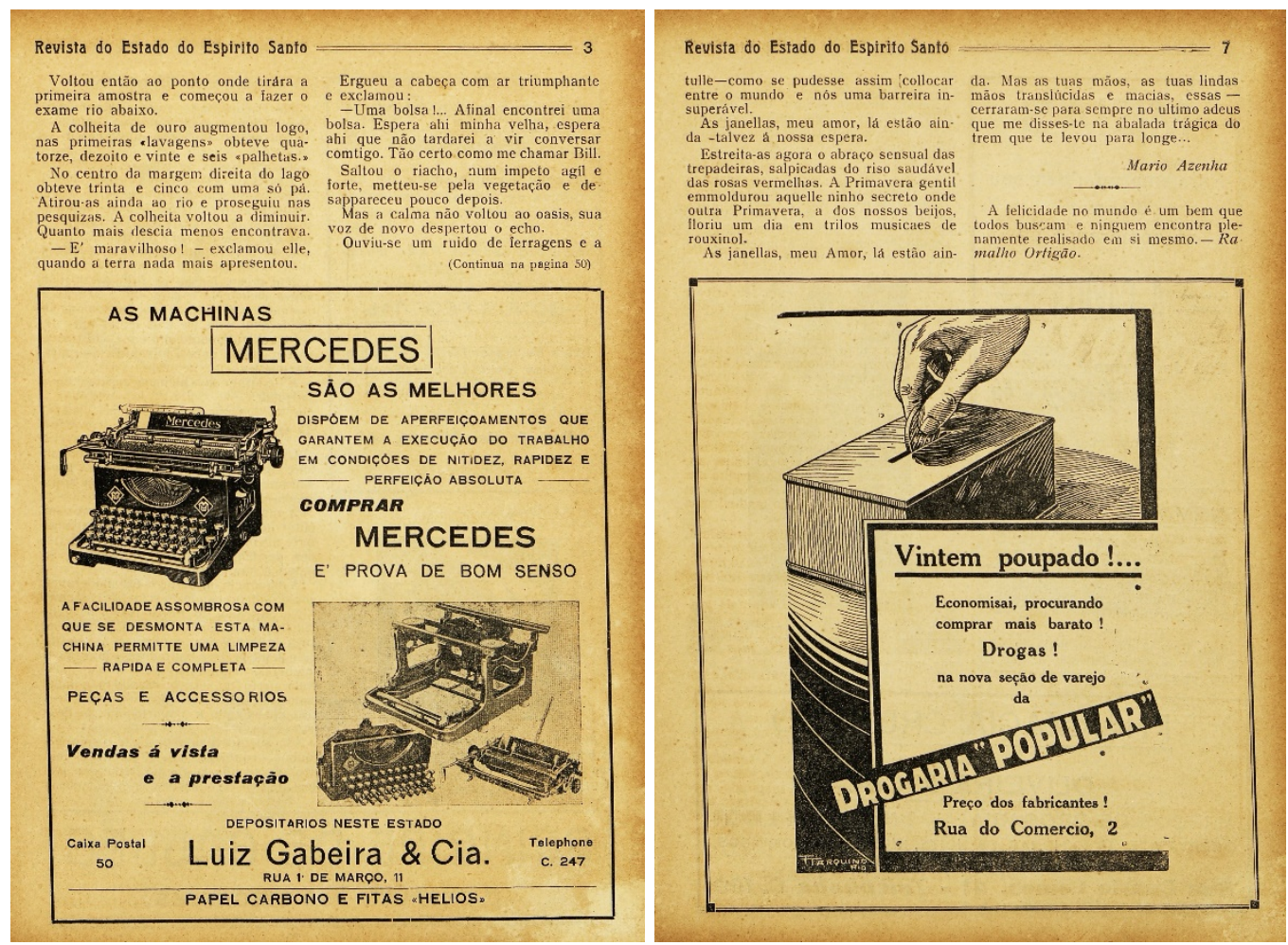

Figura 12: Revista do Estado do Espírito Santo, n¹, 1933, p. 55. Fonte: Acervo digital do Laboratório de Design: História e Tipografia (2020).

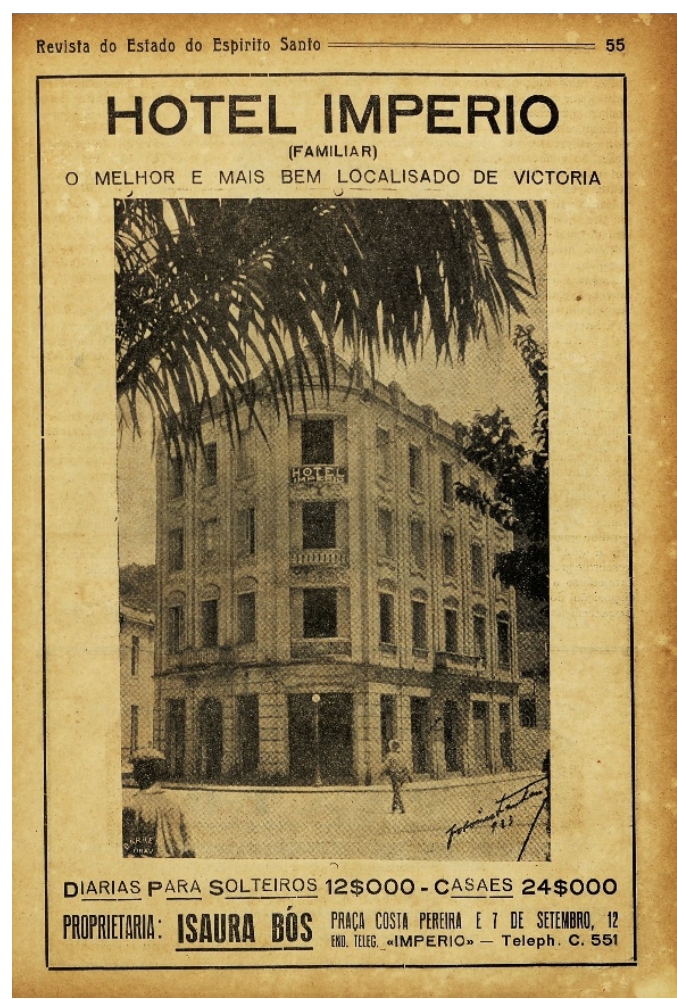




\section{Resultados}

A revista possuía um conteúdo variado com suas experimentações, como as fotomontagens e os títulos ilustrados, que davam personalidade às matérias. Seu forte cunho comercial chamava atenção pela presença exacerbada de anúncios em quase sua totalidade de páginas. Destaca-se que os anúncios imagéticos, apesar de terem sido encontrados em menor quantidade, distinguiam-se por ocupar áreas privilegiadas da revista. Há registros que o anúncio mais caro chegou a custar 200 mil réis, localizado na quarta capa.

Como pode ser observado, a revista possuía capa colorida com ilustrações pictóricas, o uso desses elementos no local de maior destaque da revista, trazem consigo um simbolismo que fazem referência ao Estado, fato evidenciado na utilização do mapa e na própria escolha do nome do periódico.

Ao longo da análise do miolo, percebeu-se que a maioria das páginas era dividida em duas colunas e os textos eram compostos com alinhamento justificado. As exceções incluíam a composição de poesias, que apresentavam alinhamento à esquerda, e em experimentações da mancha gráfica, criando formas geométricas.

\section{Considerações finais}

Conclui-se que o planejamento e as estratégias utilizadas pela revista mostram suas intenções comerciais, evidenciado pela grande quantidade de anúncios, além da descrição de seu público voltado à elite, disposto no expediente da revista, onde salienta sua distribuição gratuita ao comércio e seus clientes.

O uso de cores na capa, de experimentações gráficas no miolo, como fotomontagens e manipulações da mancha gráfica, se sobressaíram como recursos visuais utilizados com o objetivo de torná-la mais atrativa. Esses esforços para se aproximar do público capixaba refletiram os investimentos na produção gráfica do período.

Esse estudo integra as pesquisas da memória gráfica brasileira e pretende compor os resultados que revelam a prática profissional e a produção da cultura material regional na década de 1930.

\section{Referências}

Azerêdo, J. S. \& Fonseca, L. P. (2016). Análise dos anúncios da revista Chanaan. In: Congresso Brasileiro de Pesquisa e Desenvolvimento em Design, 12, p. 382-394, 2016. Anais. São Paulo: Blucher Design Proceedings, v.9, n.2.

Baptista, Í. C. Q. \& Abreu, K. C. K. (2010). História das Revistas no Brasil: um olhar sobre o segmentado mercado editorial. Biblioteca On-line de ciências da computação. http://www.bocc.ubi.pt/pag/baptista-iria-abreu-karen-a-historia-das-revistas-no-brasil.pdf 
Fonseca, L. P.; Gomes, D. D. \& Campos, A. P. (2016). Conjunto Metodológico para Pesquisa em História do Design a partir de Materiais Impressos. Revista Brasileira de Design da Informação, São Paulo, v. 13, n. 2, p. 1 - 19.

Martinuzzo, J. A. (2008). Quase 200: A Imprensa na História Capixaba. Vitória: DIO.

Porta, F. (1958). Dicionário de artes gráficas. Rio de Janeiro: Globo.

Revista do Estado do Espírito Santo (1933), Vitória, nº 1.

\section{Sobre o(a/s) autor(a/es)}

Amanda Martinelli das Neves, Bacharel, UFES, Brasil, <amandamartinelli2015@gmail.com> Letícia Pedruzzi Fonseca, Dra., Ufes, Brasil, <leticia.fonseca@ufes.br> 